\title{
LA FICCIÓN MEDIEVAL DE ARTHUR CONAN DOYLE ${ }^{1}$
}

\author{
Antonio José Miralles Pérez, Universidad Católica San Antonio de Murcia \\ Email: ajmiralles@pdi.ucam.edu
}

\begin{abstract}
Resumen: A final de la era Victoriana, cuando el nuevo siglo presentaba sus desafíos y rutas de progreso, Arthur Conan Doyle decide revivir la época de Eduardo III y el Príncipe Negro. Su estudio de la caballería y del arquero inglés genera un caudal educativo que dirige hacia los jóvenes y adultos de clase media. La reconstrucción del siglo XIV en The White Company (1891) y Sir Nigel (1906) refleja su compromiso con el honor y el deber nacional, su manera de ver la historia y la ficción, su disfrute de la aventura y la lucha, y su sentido de humor.
\end{abstract}

Palabras clave: Novela histórica, era Victoriana, siglo XIV, tradiciones nacionales, caballería, masculinidad.

Title in English: Medieval fiction in Arthur Conan Doyle

\begin{abstract}
As the Victorian age neared its end and the new century presented challenges and new courses of progress, Arthur Conan Doyle decided to revive the days of Edward III and the Black Prince. His research into chivalry and the English archer became a source of example and instruction for both young and adult middle class citizens of Britain. In the writing of The White Company (1891) and Sir Nigel (1906), he was led by his commitment to patriotic duty and honour, his consideration of history and fiction, his passion for adventure and fighting, and his sense of humour.

Keywords: Historical novel, Victorian age, fourteenth century, national traditions, chivalry, manhood.
\end{abstract}

\section{INTRODUCCIÓN}

En las postrimerías de la era victoriana el escritor emergente Arthur Conan Doyle confía en la novela histórica aprendida de Walter Scott para discutir cuestiones de importancia, como el uso del poder político, la faceta terrenal de la Iglesia, la práctica de la guerra y la conducta moral del individuo y de los grupos sociales. Cree que esta clase de ficción puede ser usada para examinar ideologías, discutir la idiosincrasia de los británicos y erigir los fundamentos del hombre. Decide situarse en el reinado de Eduardo III, una época que juzga adecuada para sus fines educativos, además de propicia para trabar diversión popular mezclando drama y comedia. Con The White Company (1891) y Sir Nigel (1906) nos trasladamos al siglo XIV de un novelista interesado en el progreso de su tiempo, atento a los avances de la ciencia y consciente de los cambios en la cultura y la sociedad; todo lo

Date of reception: 5 May 2011

Date of acceptance: 12 September 2011 
cual, según él, debe convivir con el respeto al legado de los antepasados. Valora las virtudes tradicionales y celebra que perduren; son un bien al que desea contribuir. Pero advierte de que también se perpetúan los males que sufrieron sus ancestros.

Estamos ante un hombre de fuertes convicciones y seguro de sí mismo, siempre dispuesto a expresar su desacuerdo y su aprobación, firme en las críticas y honesto en los elogios tanto a sus contemporáneos como a sus antepasados. Aunque tiende a situarse con la autoridad y las leyes, es decidido en la contestación a las mismas (tanto en la realidad como en la ficción) cuando cree que se han cometido abusos e injusticias contra los humildes y decentes. Por otra parte, no censura las ambiciones y luchas de poder de los grandes hombres ni a los que participan de su arrogancia y la pugnacidad consiguiente. De hecho, necesita posturas inflexibles y beligerantes para construir sus novelas, en las que desea que impere el conflicto y la confrontación en torno a principios críticos para la comprensión del hombre. Justifica su inclinación por la aventura de las armas esgrimiendo nociones de honor y heroísmo heredadas de la nobleza caballeresca, y construye sus propias ideas acerca de la motivación del caballero conteniendo las fantasías e ilusiones ingenuas. Maneja con habilidad sus obligaciones públicas y privadas, y asiente a la fuerza de sus promesas y juramentos (sean políticos, religiosos o incluso sentimentales); asimismo es partidario de la rigidez moral que requiere el cumplimiento de los mismos, pues de ella surge inevitablemente la animosidad contra quienes profesan otros credos e idearios.

Uno de sus principales empeños en ambas novelas es mantener el equilibrio entre el humor y la diversión por una parte, y el talante de autoridad e instrucción que, por otra parte, también es determinante en la concepción y tratamiento de la época y sus personajes. Este semblante doble puede confundir al lector, vierte irrealidad sobre individuos y escenas, y suscita dudas acerca del genio y la pericia del autor en cuanto a la selección y manejo de las líneas maestras sobre las que pretende sostener una memorable representación del siglo XIV.

\section{MASCULINIDAD, CABALLERÍA Y HEROÍSMO MILITAR}

El estudio de la masculinidad es crucial para Doyle en su ficción medieval, y a través de sus personajes predilectos opina sobre sus deberes y su integridad moral. Le interesa el compromiso patriótico y la responsabilidad social, sin descuidar, en su modelo caballeresco, la relación con la mujer, el amor y el matrimonio. ${ }^{2}$ Son temas serios en la consideración del hombre, pero Doyle no se sume en prolongadas reflexiones. Prefiere resaltar los desafíos y el viaje heroico, donde pesan más las facultades físicas y pasionales que las del espíritu o el intelecto. Así, Doyle confecciona su ficción en torno al periplo militar de sus héroes, que se definen más por la vitalidad muscular; buscan el combate, la demostración de vigor y fortaleza para vencer enemigos y obstáculos, y el triunfo que merezca reconocimiento y premios. Doyle es partidario del culto a los guerreros de la nación, y encuentra en las décadas centrales del siglo XIV personajes idóneos; ante todo, aquellos caudillos, caballeros y soldados que forjaron la epopeya inglesa de la primera etapa de la Guerra de los Cien

2 Para comprender la concepción y manejo de la caballería y el caballero por parte de Doyle, es necesario considerar la obra del cronista Jean Froissart, al que dedica unas páginas en Through the Magic Door (DOYLE 1907: 219-25).

Odisea, $n^{\circ} 12$, ISSN 1578-3820, 2011, 351-360 
Años. Comunica especial aprecio por los arqueros de ascendencia sajona, uno de los muchos lazos de unión (y cierta divergencia) con Walter Scott.

I set myself to reconstruct the archer, who has always seemed to me to be the most striking figure in English history. Of course, Scott has done him finely and inimitably in his outlaw aspect. But it was not as an outlaw that he was famous. He was primarily a soldier, one of the finest that the world has ever seen - rough, hard-drinking, hard-swearing, but full of pluck and animal spirits. The archers must have been extraordinary fellows. ${ }^{3}$

No es verdad que Scott sólo mostrara al arquero inglés como proscrito en Ivanhoe (1819). Doyle olvida el canto al triunfo del long bow que es Halidon Hill (1822). La victoria de Eduardo III sobre los escoceses en aquella batalla es un logro de sus arqueros, gente sin escudo de armas ni espuelas doradas; los mismos que merecen protagonismo en las novelas de Doyle, tanto como el que concede a los magnates e hidalgos de la caballería. Notamos su simpatía y respeto por los soldados de infantería, aunque es innegable que su paradigma de masculinidad está incompleto si omitimos las cualidades del caballero. Aunque busca ejemplaridad y excelencia, Doyle reconoce la condición humana de todos sus héroes, sea cual sea su rango o categoría. Señala defectos en el sajón y en el normando, en el clérigo y en el señor feudal; da fortaleza muscular y quita calidad moral, hace de unos figuras educativas y de otros caricaturas cómicas, y se sirve de ellos para una sucesión de simples lecciones de virtud y pecado que recorren la jerarquía social de entonces y no son extrañas en el análisis del hombre contemporáneo. ${ }^{4}$

La concepción y práctica de la guerra genera uno de los debates más interesantes de las dos novelas medievales de Doyle. La guerra como profesión y negocio contrasta con la guerra como contienda deportiva y caballeresca, y los exponentes de uno y otro lado llegan a ser antagonistas en algunos de los episodios más significativos. Doyle valora la profesionalidad y la experiencia, y no oculta sus reservas hacia los que ven en la guerra una diversión o un juego y no se preocupan de conocer su ciencia, tácticas y disciplina. Doyle aboga por hombres correctamente motivados y que sean capaces de realizar la tarea, preparados para aceptar el cambio del mundo civil al militar y cumplir sus reglas. Entre las características del caballero óptimo que Doyle propugna están una sensatez madura y una decisión lúcida que ingenuamente cree fruto de la educación moral (en la que minimiza la preceptiva cristiana) y de la experiencia en la actividad militar surgida del honor y del patriotismo. Advierte de que las pasiones que contravienen esta virtud conducen al desastre. Observamos a los caballeros jóvenes forzados a seguir un orden de combate, unas tácticas serias y unas pautas de obediencia y colaboración que anulan su impulsividad y arrojo heroico. Merece la desaprobación del autor el que no se esfuerza por mantener la calma y controlar su nervio en la guerra, cuando están en juego el destino de una nación y la vida y dignidad de muchos.

Fragmento de la entrevista realizada por H. How, 'A Day with Dr Conan Doyle,' que fue publicada en The Strand Magazine: An Illustrated Monthly, vol. IV, págs. 182-8, en agosto de 1892, y que H. Orel reproduce en Sir Arthur Conan Doyle: Interviews and Recollections (OREL 1991: 62-8).

4 Sirvan de ejemplo el retrato del abad Berghersh (DOYLE 1891: 5-7) y el del señor de Villefranche (DOYLE 1891: 362). Éste último es uno de los sujetos que utiliza el autor para analizar la constitución social y militar del caballero. 
Una de las figuras históricas utilizadas por Doyle en sus novelas medievales es el caballero inglés Sir John Chandos. Hace de él un maestro capaz de enseñar las claves de una caballería útil en un mundo distinto al de los romances. ${ }^{5}$ Sin embargo, el personaje central, Nigel Loring, sigue fiel, en su juventud y aún en la edad adulta, a la literatura idealista y a sus afanes de protagonismo heroico; y por ello se resiste a acatar el conjunto de imperativos de prudencia, disciplina, táctica y cautela que dicta el saber militar. Para Doyle, este singular hidalgo caballeresco es un sujeto que suscita asentimiento en unas ocasiones aunque también puede ser tachado de insensato y ridículo en otras; encarna los méritos y desatinos de la caballería y refleja la pugna esencial entre realidad y romance.

El aprecio por los combatientes ingleses no le impide a Doyle valorar a los extranjeros que figuran en su elenco de caballeros y militares. En ellos también aplaude la lucidez, la valentía, la destreza y el aguante físico y mental. Evita mostrar delectación en la crueldad del hombre hacia su enemigo, al menos en los personajes que utiliza para divulgar sus nociones de recta hombría. No percibimos desprecio hacia otras razas y culturas, y sí respeto y admiración por pueblos de los que es posible aprender si se elude el influjo de prejuicios y estereotipos. Esto merece atención en el marco de las contiendas imperialistas del cambio de siglo, donde a juicio de Doyle todavía son válidas sus nociones clásicas de masculinidad, caballería y heroísmo militar.

\section{PERSPECTIVAS PATRIÓTICAS, DE CLASE Y LITERARIAS SOBRE EL PASADO Y EL PRESENTE}

Es palpable el orgullo patriótico de Doyle en las dos novelas, si bien no excede la sobriedad y moderación que orientan su tratamiento del pasado. En cuanto al enfrentamiento entre naciones, no le horroriza porque tiene confianza en la deportividad y la nobleza de los contrincantes, pese a que realmente extienden su dominio el fanatismo, el odio y el ansia de supremacía. Con la mirada entre el pasado y el presente, Doyle no quiere que Gran Bretaña sea una potencia arrolladora y tiránica, pero tampoco que pierda fuerza y sean otros los que afirmen su dominio en el mundo. Sabe que hay enemigos formidables dispuestos a frenar la expansión británica y reducir su poder. Ante esta realidad, en su ficción Doyle mantiene la moral de los suyos, alienta su confianza en la victoria, y los anima a aprender de sus antepasados.

I consider it was the most glorious epoch in English history. The English alone were never so strong as just then.

It seemed to me that the days of Edward III constituted the greatest epoch in English history - an epoch when both the French and the Scottish kings were prisoners in London. ${ }^{6}$

\footnotetext{
La función educativa de este personaje sobresale en varios episodios de Sir Nigel (DOYLE 1906: 60-4, 160-2).

6 Doyle mantuvo esta opinión a lo largo de las décadas. La primera parte de la cita procede de la entrevista realizada por R. Balthwayt, 'A Talk with Dr Conan Doyle', publicada en The Bookman, II, nº 8, págs. 50-1, en mayo de 1892, y que H. Orel reproduce (OREL 1991: 57-60). Las otras líneas han sido extraídas de la autobiografía de Doyle, Memories and Adventures (DOYLE 1924: 67).
}

Odisea, $n^{\circ} 12$, ISSN 1578-3820, 2011, 351-360 
Doyle recuerda tiempos de esplendor y tiene esperanzas en el futuro de su país. A través del relato novelesco del pasado transmite reflexiones y advertencias sobre el presente, y desea influir en la conciencia de sus compatriotas con la seguridad de haber adoptado una postura, a su juicio, muy patriótica. Al situarse a mediados del siglo XIV, Doyle escoge una época importante para la nación y conveniente ahora que desea ver el fortalecimiento de su identidad. Le atrae el vigor de la vieja épica, e incorpora componentes del romance caballeresco posterior que no perjudiquen su intención de ceñirse a la historia. A finales del siglo XIX aún piensa que la novela histórica no ha perdido sus virtudes ni el prestigio que Walter Scott lograse para ella. Confía en las bondades de su influencia para guiar su labor en la reproducción de la época, la invención de personajes y la composición de sus aventuras y luchas. Su propósito no es entretener como un juglar, ni se dirige a una audiencia púber o adolescente incapaz de distinguir significado más allá del divertimento. La novela histórica exige un esfuerzo intelectual y una aplicación de su talento literario que sólo puede apreciar el lector adulto y cultivado. Concibe su audiencia en la clase media del cambio de siglo, suficientemente instruida para disfrutar la narración y percibir los méritos de una obra que pretende equilibrar el estudio histórico riguroso y la creación novelesca edificante.

A propósito de la clase media victoriana, Doyle es consciente de que abundan los deseos de elevación social, e incluso existen pretensiones nobiliarias. Así que no faltan quienes sienten o se inclinan por los valores asociados a la aristocracia. Se constata la paradoja de que individuos que se involucran plenamente en el progreso del mundo industrial no abominan de la vieja sociedad de estamentos jerarquizados, y tratan de imitar los hábitos y la cultura de las familias de pedigrí. Éstas resisten el cambio de los tiempos y la irremediable decadencia apegándose a su historia, su patrimonio, sus tradiciones y sus normas de vida. Otros en la clase media victoriana entienden su identidad social de otra manera y no aspiran a la distinción heráldica ni a levantar una imponente residencia señorial en la campiña. En su recreación del pasado, Doyle no puede ignorar a los que, en los albores de un nuevo siglo, no quieren permanencia para el rancio y lamentable legado de la clase nobiliaria, con sus iniquidades, egoísmos, privilegios inmerecidos y abusos seculares. Es el enemigo a batir de los que constituyen esa burguesía más libre y segura de sí misma, volcada en el aumento de sus derechos y bienes y en la justa valoración de sus méritos profesionales y de sus cualidades ciudadanas.

A pesar del humor que impregna numerosos episodios de sus novelas medievales, y a pesar de que abundan en ellas los lances de intrepidez, pasión y enfrentamiento cercanos al romance de aventuras juvenil, Doyle asegura su compromiso con el rigor y la seriedad en su recreación de ese siglo XIV en el que ha puesto su interés. Se propone describir con precisión el carácter del mismo asumiendo el esfuerzo de la investigación histórica; se rodea de libros y les dedica mucho tiempo. No obtuvo, sin embargo, ni con The White Company ni con Sir Nigel, todo el elogio que esperaba para elevar su categoría literaria.

I shall send you the cuttings about The White Company ... They are none of them hostile \& yet I am disappointed. They treat it too much as a mere book of adventure -as if it were an ordinary boys book- whereas I have strived to draw the exact types of character of the folk then living \& have spent much work and pains over it, which seems 
so far to be quite unappreciated by the critics. They do not realise how conscientious my work has been. ${ }^{7}$

Doyle manifiesta su preocupación y compromiso con la exactitud de los detalles históricos: hábitos sociales, actividad militar, vestimenta, heráldica, etc. Y detrás de todo ello está el espíritu y el carácter de la época, de la gente retratada y de sus decisiones y actos. En su propósito hay un lector educado que sabe reconocer la congruencia, la fidelidad y el conocimiento meticuloso de la época y de sus hombres. Doyle cree que existe la verdad histórica y puede descubrirse mediante un trabajo diligente y honesto, minucioso y responsable de principio a fin. Así quiere distanciarse de los que cometen inexactitudes y errores por ignorancia, falta de cuidado, excesiva licencia, etc. Su objeto no son los laxos y fantasiosos romances caballerescos sino la realidad del siglo XIV, a la que se cree vinculado y a la que debe facetas sustanciosas de su personalidad. Por otra parte, es erróneo afirmar que Doyle procede con plena imparcialidad en su recreación de aquel periodo, en el sentido de que no quiere ser un observador distanciado, libre de condicionantes ideológicos y sin motivos para implicarse. Percibimos sus preferencias y simpatías ante las figuras principales de ambas novelas y también ante la colección de personajes que entran y salen de sus escenarios.

\section{LA PERSONALIDAD Y EL PRISMA MORAL DEL ESCRITOR}

La determinación moral y educativa que guía a Doyle explica la sobriedad predominante en las novelas. Sin embargo, tienen una relevancia notable los componentes de comedia y parodia que introduce, a menudo con efectos desconcertantes sobre los lectores no acostumbrados a tanta flexibilidad o inconsistencia en el tono del relato. Sea nuestro parecer más o menos favorable, es obvio que Doyle, autor con un peculiar sentido del humor, encuentra unos fecundos motivos para la burla y la caricatura en las rarezas del romance caballeresco, sus pautas y la mentalidad de sus personajes. ${ }^{8}$ No tuvo dificultades para ridiculizar un género intrínsecamente proclive al exceso en las emociones y los comportamientos. No negamos que las razones que impulsan el relato pueden estar llenas de virtud y justicia, pero dado que no hay integridad ni perfección surgen los errores y las desviaciones, a las que Doyle da fácilmente un tono paródico y jocoso. Estas concesiones al extravío inocuo y la comicidad pasajera no estropean, sin embargo, la deliberación de la finalidad educativa que se introduce inequívocamente en la narración y tiene acentos de insistencia cuando se ocupa de las cuestiones que considera cruciales para el individuo. Una de ellas es la familia.

Doyle concede mucho valor a la familia, su legado y sus tradiciones vinculadas a la nación. Reconoce en el ámbito doméstico la importancia de la mujer, pero afirma con la gentileza precisa que no ha de limitar la libertad del hombre para cumplir su destino o

\footnotetext{
Fragmento de una carta de Doyle a su madre fechada el 11 de noviembre de 1891; reproducida en Arthur Conan Doyle: A Life in Letters (LELLENBERG, STASHOWER \& FOLEY 2007: 300-1).

$8 \quad$ Entre los muchos episodios que ilustran esta cuestión, sugerimos el protagonizado por Nigel Loring junto al puente de Tilford (DOYLE 1906: 93-101) y su frustrado lance de armas con el señor de Pons (DOYLE 1906: 155-8).
}

Odisea, $n^{\circ} 12$, ISSN 1578-3820, 2011, 351-360 
dedicarse al honor. El hogar no puede retener a los varones que se ajustan a su paradigma; los anima a volcarse en la aventura y el heroísmo para realizarse adecuadamente y para servir a la nación. Por su parte, la mujer suele ser una figura cabal que asume la impropiedad de exigir cuando se espera sumisión y gratitud. El hecho de que algunos caballeros de romance no podían apartar de su pensamiento la imagen de la doncella amada no afecta demasiado a Doyle, en cuya ficción medieval ni siquiera el joven Nigel Loring se sume en pensamientos de amor hasta olvidarse de lo que tiene alrededor. El amor no es tan poderoso como para quitarle la cordura y llenarlo de nostalgia y pesar. En vez de cargarse de preocupaciones de las que culpar a la mujer, confía en ella y tiene tranquilidad para avanzar en su viaje de caballería. En éste, frente a la comodidad doméstica y el cuidado de la esposa, vemos un elogio de la austeridad, el esfuerzo y la bravura. A este deber se aplica el caballero fuera de casa, resistiéndose al hecho de que con los años el cuerpo quiere más descanso, mejor comida, abrigo y ocio. Con los principios intactos, el Loring de mediana edad sigue embarcándose en las campañas bélicas de sus príncipes aceptando todo el empeño y abnegación que exigen. Así quiere Doyle dar ejemplo; afirma que es posible perseverar en las lealtades y juramentos a lo largo de los años. Sin claudicar ante las desilusiones de la experiencia y las vilezas inextirpables del ser humano, Doyle anima a la coherencia y el aguante en la rectitud con la que el individuo se compromete al formar su identidad.

Hay facetas de la naturaleza humana en las que Doyle no quiere detenerse excesivamente. Pero su retrato del hombre medieval sería falso si omitiese sus bajezas y perversiones. Todos los pecados están vivamente representados en las novelas, normalmente con la intención de subrayar que una de las obligaciones del caballero es mantenerse alejado de ellos. Loring está cerca de este ideal, pero los caballeros con los que se encuentra muestran distintas imperfecciones típicas de la condición humana, así como desviaciones con respecto a las normas de conciencia y conducta de las que depende la superioridad de su rango. Considerando a los nobles y también a otros grupos, Doyle se propone dar lecciones de integridad, y forma parte de las mismas exponer los defectos y bajezas del hombre, a veces señalando la relevancia del origen y crianza del individuo. Ejemplo de ello es la sexualidad, que sirve a Doyle para destacar diferencias de clase y talante ético entre sus protagonistas: Nigel Loring y Samkin Aylward. Frente a la ligereza de este plebeyo-arquero, el hidalgocaballero se presenta como ejemplo de devoción a una sola mujer. Doyle le concede la entereza necesaria para no abandonarse a pasiones vulgares; carece de la incontinencia del villano y asume una templada norma sexual que se integra en la moralidad del paradigma masculino que Doyle defiende, en el que la influencia de la mujer es más espiritual que erótica. Sin embargo, en la desinhibida promiscuidad de Aylward encontramos otra clase de hombría, que no se somete a los mandatos del clero ni aprecia ejemplaridad en la nobleza. ${ }^{9}$ Doyle, fiel a sus propios preceptos, adherido al honor y la decencia que desea inculcar, se inclina por la corrección de su caballero sin ceder a la disipación del otro. Tiene hacia él, no obstante, una actitud benévola y permisiva, pues en vez de abominar de su afición a las mujeres le da un tono cómico y despreocupado, evitando la degradación ofensiva en la que a menudo termina el varón incapaz de controlar sus apetitos. Está mucho más cómodo

\footnotetext{
El contraste entre los dos personajes es palpable en este tema (DOYLE 1906: 141-2) como en tantos otros, aunque no se convierte en manos del escritor en motivo de enfrentamiento. Prefiere alentar la concordia y el buen humor en individuos a los que concibe complementarios pese a sus diferencias ideológicas y morales.
} 
Doyle cuando refuerza el compromiso con la virtud, en la que la mujer tiene una relevancia enorme. Por el sosiego que inspira, puede el caballero optar siempre por el camino más difícil, el que exige más esfuerzo y constancia, siendo la aprobación de ella una recompensa superior a la de cualquier credo o confesión.

La religión y la Iglesia constituyen otro tema de interés para Doyle en la caracterización del hombre medieval. Encontramos reflexiones sobre lo divino y lo humano y sobre la relación entre fieles, no creyentes y clérigos de distinta índole. Doyle maneja las divergencias entre personajes sujetos a las reglas eclesiales y personajes que siguen su propio código o criterio. La discrepancia y la contradicción abundan entre los hombres de toda extracción. Quienes deberían obedecer las normas religiosas y complacer al clero a menudo prefieren el dictamen de su propia voluntad, y si tienen poder para actuar con esa libertad, hacen uso de él. No obstante, saben que no les conviene desentenderse completamente de la fe. Algunos refuerzan su determinación personal con súplicas e imploraciones de amparo y protección; tienen la necesidad, más o menos sincera, de que Dios o ciertos santos guíen sus pasos y los guarden durante sus viajes y empresas. ${ }^{10}$ Además, a la hora de afrontar los retos de la aventura, a los rezos y plegarias se unen augurios y presagios, influjos que resultan útiles para generar tensión e incertidumbre en el avance de algunos héroes. Sabemos que, de acuerdo con la ortodoxia caballeresca, el hidalgo ha de ser hombre piadoso. Pero es evidente que Doyle propugna el derecho y la fuerza del individuo para gobernar su vida sin someterse a las normas de otros. No puede sostener por tanto la idea de que por la fe el caballero evita la maldad y se entrega a las causas de la Iglesia. Oponiéndose a su predominio moral, Doyle duda de que lo que anima al caballero a realizar actos de nobleza en vez de crímenes sea el apego a la Iglesia, un discernimiento aprendido del clero y la confianza en la bondad de Dios. Aunque puede respetar la espiritualidad privada del caballero como fundamento de su rectitud, desconfía de un clero que se inmiscuye en la vida del individuo y pretende dirigir su conducta en la paz y en la guerra.

Aunque para unos pocos el viaje a la guerra va acompañado de ilusiones nacidas de cuentos y romances, Doyle se atiene a su compromiso con la realidad. Recrea lugares de inmundicia, odio y desesperación donde es común presenciar la depravación del hombre y el fin del insensato amor caballeresco por el desafío y el noble enfrentamiento en tierras inhóspitas y peligrosas. Aquí tiene relevancia otro tema de discusión para Doyle: aunque defiende la virtud que puede existir en las reglas del caballero íntegro, explota el conflicto provocado por los que carecen del espíritu que se opone al deshonor en la conducta bélica. ${ }^{11} \mathrm{Ni}$ él ni Loring pueden perderse en necias fantasías para no plantar cara a los que degeneran y cometen actos contrarios a la ética caballeresca en la guerra y sus aledaños. Y sin embargo, resulta arriesgado, invita a la reacción, proponer que sea el noble y caballero, frecuente perpetrador, quien deba impedir excesos y desmanes. A Doyle le interesa la responsabilidad que soportan los hombres de rango. Supuestamente, están dotados de sabiduría y juicio, así como de capacidad para el esfuerzo y la perseverancia. Ante los jóvenes de clase media de su tiempo, Doyle intenta

\footnotetext{
10 Pese al poder eclesial, Doyle permite gestos de irreverencia hacia la Iglesia y reconoce el peso de las supersticiones paganas en el corazón de aquellos hombres (DOYLE 1891: 200-4).

11 El novelista explota abiertamente el caudal dramático procedente de los impíos, viles e inmorales que abundan en las tierras de conflicto armado. Individuos como Sir Tristram de Rochefort (DOYLE 1891: 362 y ss.) y Oliver de St Yvon (DOYLE 1906: 248 y ss.) tienen una caracterización tan fuerte que al menos durante unas páginas dominan los acontecimientos exhibiendo sin pudor todos sus excesos y transgresiones.
}

Odisea, $n^{\circ} 12$, ISSN 1578-3820, 2011, 351-360 
edificar la ejemplaridad del caballero, respaldando la proposición de que ha de ser un hombre de virtud y honor, consciente de sus obligaciones, dispuesto a probar la calidad que se le supone en toda su experiencia, y reacio a ceder frente a descreídos y déspotas.

\section{CONCLUSIONES}

La lectura de estas novelas nos descubre el espíritu de un escritor para muchos ahora viejo y trasnochado, aunque su intención merece aún algunas reflexiones. Doyle propone aprender del buen caballero y sus acciones, concebidas como pruebas de valor y mérito, como actos heroicos por su esfuerzo, peligro y desgaste. También se percibe en ellas voluntad de resistencia frente a la vileza y disipación de otros. Aunque tildado de necio e ingenuo, Doyle no renuncia a su deseo de enseñar una vida honorable en la que es natural soportar fatiga y adversidad, y donde hay ánimo de apartarse de actos innobles, bajos placeres y costumbres sin moderación. En personajes como Loring sobresale una idea clara del honor, y es significativo el hecho de que la fidelidad a éste puede superar la lealtad hacia la Corona, alto estamento de autoridad desde el que se dictan las reglas a cumplir por hidalgos y caballeros como aquel. Doyle también ejerce su propia autoridad, aunque a menudo es prudente y se limita al asentimiento, como si no hubiese nada que enmendar en la tradición. Con esta cautela confirma que entre los atributos del héroe caballeresco está tanto el valor físico que empuja al combate como el convencimiento moral que orienta la conducta.

Sin embargo, es más interesante la recreación literaria del caballero medieval cuando Doyle examina sus facetas contradictorias y cambiantes y no se afana en conservar supuestos atributos fundamentales del arquetipo. Oscila entonces entre un estudio crítico y personal del mismo y una suerte de tácito compromiso con las características que constituirían su identidad permanente, el reflejo quizás de una parte esencial del hombre libre de alteraciones en el desarrollo histórico. El énfasis es claro en las decisiones que marcan al individuo y la seriedad con que debe ejercer su libertad. Así se comunican mensajes quizá demasiado teñidos de ideología, pero en los que Doyle cree abiertamente. Si está convencido de que hay lazos de honor que deben encauzar el esfuerzo más allá del beneficio particular, lo dice. Alienta la nobleza del hombre en una realidad cargada de violencia, obstinación y otros excesos. Le preocupa la discordia en su país y el control de la fuerza cuando su gente recorre otras tierras. Necesita afianzar su certeza moral para que, tras situarnos en conflictos distantes, pueda atraernos a las peripecias de sus héroes mientras elabora, con las diferencias y semejanzas de ayer y hoy, lecciones cómodamente digeribles. Es libre para ejercer todas sus facultades de autor. Y con tal potencia a su disposición, argumenta su sentido del deber y de la justicia, explica los orígenes de la dignidad que ha adoptado y quiere divulgar, y modela a sus antepasados con un afán de edificación patriótica que solamente frena la vergüenza de alterar la historia con mentiras.

\section{REFERENCIAS BIBLIOGRÁFICAS}

Doyle, A. C. 1891. The White Company. Nueva York: Thomas Y. Crowell \& Co.

---. 1906. Sir Nigel. Toronto: William Briggs.

Odisea, ${ }^{\circ} 12$, ISSN 1578-3820, 2011, 351-360 
---. 1907, ed. 1999. Through the Magic Door. Nueva York: The Akadine Press Inc.

---. 1924, ed. 1989. Memories and Adventures. Oxford: Oxford University Press.

Froissart, J. 1373-1400, ed. 1901. Chronicles of England, France, Spain and the Adjoining Countries. Trans. Thomas Johnes. Londes y Nueva York: The Colonial Press.

Lellenberg, J., D. Stashower y C. Foley, eds. 2007. Arthur Conan Doyle: A Life in Letters. Londres: Harper Press.

Orel, H., ed. 1991. Sir Arthur Conan Doyle: Interviews and Recollections. Basingstoke: Macmillan Academic \& Professional, Ltd.

Scotт, W. 1819, ed. 1906. Ivanhoe. Boston: Ginn \& Company.

---. 1822. Halidon Hill: A Dramatic Sketch from Scottish History. Nueva York: Samuel Campbell \& Co. 